\title{
INTERPRETAÇÃO DO MUNDO E PROJETOS DE FUTURO DOS AVA-GUARANI DE OCO' $\mathrm{Y}^{1}$
}

\author{
ADRIANA REPELEVICZ ALBERNAZ ${ }^{2}$
}

UFSC

\begin{abstract}
RESUMO: A literatura etnológica sobre os Guarani afirma que eles tem uma temporalidade cíclica e que eles são pessimistas em relação ao futuro, em função de sua perspectiva cataclísmica (NIMUENDAJU, 1987; METRAUX, 1967). Entretanto, os Ava-Guarani de Oco'y (oeste do Paraná), que têm uma história recente de expulsões de lugares de ocupação tradicional e de luta para a conquista de um território para seu assentamento, diferenciam-se deste modelo etnológico na medida que apresentam projetos para o futuro que provam que eles não esperam resignadamente o próximo cataclismo. Eles afirmam que a terra irá queimar, mas agora não por um designo divino, mas devido às devastações provocadas pelos "brancos" que deixam a terra sem proteção. Sobre esta mudança de perspectiva que este artigo versará.
\end{abstract}

PALAVRAS-CHAVE: perspectiva cataclísmica Guarani; temporalidade cíclica; temporalidade histórica; chefia indígena.

\begin{abstract}
The ethnological literature about the Guarani to say that they have a cyclical temporality and that they are pessimistic in relation to the future, in function of their cataclysmic perspective (NIMUENDAJU, 1987; METRAUX, 1967). However, the Ava-Guarani of Oco'y (Parana's west), that have an recent history of expulsions of traditional occupation's places and of fight to the conquest of a territory for its settlement, they differ of this ethnological model in the measurement of they present project to the future, that prove that they not wait with resignation the next cataclysm. They say that the earth is going to burn, but now not because of a divine designation, but due to the devastation provoked for the "whites" the left without protection. This article will treat this perspective's change.
\end{abstract}

KEYWORDS: Guarani cataclysmic perspective; cyclical temporality; historical temporality; indigenous leadership.

\section{Introdução: Os caminhos que levaram à super-lotação da área indígena Ava-Guarani de Oco'y}

\footnotetext{
${ }^{1}$ Este texto foi escrito durante o período $\left(1^{\circ}\right.$. Março a 31 de junho de 2007) de estágio de doutorado no exterior na Universidade de Paris X / Nanterre, em Paris, com bolsa concedida pela Coordenação de Aperfeiçoamento Pessoal de Nível Superior - CAPES.

${ }_{2}$ Mestre em antropologia social pelo PPGAS/UFPR e doutoranda em antropologia social no PPGAS/UFSC. E-mail: adrialbernaz@yahoo.fr .
}

Espaço Ameríndio, Porto Alegre, v. 1, n. 1, p. 146-169, jul./dez. 2007. 
ADRIANA REPELEVICZ ALBERNAZ - Interpretação do mundo e projetos ...

Os Ava-Guarani que habitam desde 1982 a área indígena AvaGuarani de Oco'y, no município de São Miguel do Iguaçu, oeste do Estado do Paraná, Brasil, mais conhecidos pela literatura etnológica como Nhandéva, compõem juntamente com - como são conhecidos no Brasil - os Kaiowá e os Mbyá, o grupo indígena de língua Guarani, que faz parte da família lingüística Tupi-Guarani e do tronco lingüístico Tupi. Embora um levantamento exato da população total que compõe o grupo indígena de língua Guarani seja difícil, como afirmam Valéria Assis e Ivori Garlet (2004, p. 39-40), devido principalmente à resistência que estes indígenas apresentam as quantificações (afirmam que são formas para os controlar), e também aos deslocamentos feitos pelos membros deste grupo, estes autores apresentam o número aproximado de 65.000 indivíduos dos três subgrupos que habitam o Brasil, o Paraguai e a Argentina, em no mínimo 360 lugares. Os Nhandéva, que são conhecidos também como Chiripá, Xiripá, Ava-Katu-ete, Ava, ou Avá-Chiripá (ASSIS \& GARLET, 2004, p. 37) - de acordo com os dados demográficos apresentados pelo artigo citado acima - são no Brasil em torno a 6.300 indivíduos habitando os estados do Mato Grosso do Sul, São Paulo, Paraná, Santa Catarina e Rio Grande do Sul. No Paraguai eles são em torno de 9.000 e na Argentina eles são aproximativamente 350, formando assim um total de 15.650 indivíduos, o que os faz o menor subgrupo Guarani, já que os Mbyá são, nestes três paises, cerca de 19.000 e os Kaiowá, cerca de 29.000. Embora os Ava-Guarani sejam correntemente conhecidos como Nhandéva pela literatura etnológica, os que habitam em Oco'y não se reconhecem como tal, pois dizem que Nhandéva é um termo que designa aqueles que são parentes (nosso parente) e não o seu povo. Alguns dos indígenas que moram em Oco'y dizem ainda que a denominação Ava-Guarani é um equivoco nascido do jeito que os paraguaios chamam os indígenas Guarani e que isto se deve porque - no Paraguai, pais bilíngüe ${ }^{3}$, todos desde 1991 (NAVARRO, 2004) têm noções sobre a língua Guarani na escola primária - eles conhecem a língua Guarani, e por isto os chamam de Ava, que significa, na língua Guarani, homem. Uma Ava-Guarani afirmou-me que os primeiros habitantes desta terra, ou seja, eles mesmos eram (e em

\footnotetext{
${ }^{3}$ O Paraguai é oficialmente um país bilíngüe (línguas oficiais: Guarani e Espanhol) desde a Constituição Nacional de 1992.
} 
ADRIANA REPELEVICZ ALBERNAZ - Interpretação do mundo e projetos ...

alguns lugares mais afastados do Paraguai ainda são) chamados de Ipykué. Este seria o verdadeiro termo de auto-denominação dos Guarani. Porém, a maioria dos que moram em Oco'y aceitam a denominação, e nos rituais de reza é comum ouvir o (a) oporaíva (a) xamã ou pajé - falar o termo Ava Chiripá Guarani, referindo-se ao grupo de Oco'y. Utilizarei aqui o termo Ava-Guarani por ser o nome mais comum como eles mesmos se auto-referem e por dar o nome para a área indígena onde habitam.

Cerca de 650 Ava-Guarani $^{4}$ habitam os 231 hectares da terra indígena Ava-Guarani de Oco'y, uma estreita faixa de terra localizada entre as margens de uns dos braços do lago da Usina Hidrelétrica de Itaipu - formado pela construção desta hidroelétrica em 1982 -, e o limite colocado pelas fazendas do entorno, onde se pratica a agricultura de grande escala. A questão dos limites da área indígena de Oco’y é um problema desde sua criação, quando apenas algumas das famílias indígenas que viviam em uma das áreas que seriam alagadas pelo lago da Usina Hidrelétrica Itaipu Binacional, conhecida como Jacutinga - que, segundo o relato dos Ava-Guarani que habitam em Oco'y, tinha 1500 hectares - foram transferidas para as margens de onde seria 0 reservatório desta Usina Hidrelétrica (BRANT DE CARVALHO, 2004, p. 15). Porém a área que foi destinada aos que habitavam em Jacutinga, por não ter um tamanho adequado à organização do sistema social indígena, era imprópria para assentar este grupo, mesmo que só tomando em consideração as apenas 5 famílias das que viviam em Jacutinga que foram transferidas (neste primeiro momento) para Oco'y.

Segundo o parecer do antropólogo Edgar A. de Carvalho, que atendendo ao pedido do Conselho Indigenista Missionário e da Comissão de Justiça e Paz do Paraná, designado pela Associação Brasileira de Antropologia (ABA) para averiguar os dados fornecidos pela Fundação Nacional do Índio, este último órgão utilizou-se de categorias preconceituosas que não consideraram muitos dos que ali residiam como indígenas. Nas suas palavras:

Munidos de um conjunto de itens formais que não atestam de forma alguma a historicidade de qualquer

\footnotetext{
${ }^{4}$ Durante meu trabalho de campo, apenas duas pessoas foram apresentadas à mim como mbyá, sendo que uma destas disse-me que não é mbyá puro porque o pai de sua mãe era brasileiro.
} 
ADRIANA REPELEVICZ ALBERNAZ - Interpretação do mundo e projetos ...

grupo indígena deste país, os Guarani de Oco'y também receberam seu diploma de índios. Mas este diploma foi concedido a apenas cinco (famílias), aos quais se pretende outorgar títulos gratuitos (...). Os demais foram sumariamente desclassificados (CARVALHO, 1981, p. 09).

Assim, a área que foi destinada aos que eram oriundos de Jacutinga teve a justificativa de atender apenas a estas 5 famílias, não considerando aquelas que já haviam saído de Jacutinga e as famílias que ainda estavam ali - 13 famílias, segundo três lideranças indígenas que na época foram até o escritório da Funai em Curitiba para reivindicar o direito à terra (periódico Luta Indígena de 1982, p. 05) - , que foram classificadas pelo funcionário da Fundação Nacional do Índio, Célio Horst, como não indígenas (CARVALHO, 1981, p. 09).

Entretanto existiram dois momentos específicos de diáspora dos que viviam na área indígena de Jacutinga, antes da transferência oficial realizada pela Usina Hidrelétrica de Itaipu Binacional, segundo os relatos dos Ava-Guarani. O primeiro se deu pela pressão feita pelo Instituto Nacional de Colonização e Reforma Agrária (INCRA), por volta de 1975, que destinou a área que era habitada pelos Ava-Guarani à criação de pequenos lotes para alojar os agricultores que haviam sido retirados do local onde foi fundado o Parque Nacional do Iguaçu em 1939. O segundo aconteceu quando começaram a circular as notícias de que o local onde habitavam seria alagado. Mediante estas duas formas de pressão, vários Ava-Guarani abandonaram Jacutinga.

O primeiro momento de pressões, segundo estes indígenas, envolveu conflitos e inclusive morte de lideranças indígenas, o que motivou algumas famílias a se refugiaram em lugares mais próximos ao rio Jacutinga-Oco'y. Porém a maioria das pessoas que moravam em Jacutinga neste período - segundo as afirmações diretas dos AvaGuarani e também a partir do resgate da história de vida destes feito através do mapeamento genealógico - , se sentindo pressionados pelo Instituto Nacional de Colonização e Reforma Agrária (INCRA), saíram do local onde habitavam: entre estes, alguns foram trabalhar na agricultura nas propriedades dos colonos ${ }^{5}$ da região, e outros se encaminharam

\footnotetext{
${ }^{5}$ Nome para pequenos ou médios agricultores que na sua maioria são descendentes ou mesmo imigrantes europeus, responsáveis pela maior parte do contingente populacional da região, principalmente o relacionado ao campo.
} 
ADRIANA REPELEVICZ ALBERNAZ - Interpretação do mundo e projetos ...

para áreas indígenas do Paraguai e da Argentina. $O$ destino dos indígenas que saíram de Jacutinga no segundo momento de pressão, quando começaram a circular as notícias de que aquele local seria alagado, foi o mesmo dos que saíram na época das pressões do Instituto Nacional de Colonização e Reforma Agrária (INCRA): trabalhar para os colonos da região ou buscar parentes que habitavam em áreas indígenas do Paraguai e da Argentina.

Houve ainda, antes da transferência oficial dos Ava-Guarani que habitavam em Jacutinga para Oco'y realizada em 1982, a iniciativa por parte do órgão indigenista oficial de transferir algumas famílias indígenas para áreas onde habitavam os Mbyá, outro subgrupo Guarani, ou mesmo para áreas onde habitavam os Kaigang, grupo indígena de outra etnia e reconhecidos inimigos históricos dos Guarani. A grande maioria das famílias que foram transferidas para estas outras áreas indígenas retornou para a região oeste do Paraná - alguns ainda para Jacutinga, outros para a já criada terra indígena de Oco'y -, pois não se adaptaram à situação de subserviência aos grupos que já habitavam aquelas áreas indígenas (CARVALHO, 1981, p. 08, BRANT DE CARVALHO, 2004, p. 16).

A transferência de indígenas de Jacutinga para outras áreas, assim como a saída de Jacutinga para trabalhar para colonos da região, ou para ir morar nas áreas indígenas do Paraguai e da Argentina - pelos motivos expostos acima -, fez com que o número de pessoas que não foram consideradas quando do estabelecimento dos limites territoriais da área indígena de Oco'y aumentasse ainda mais. Entretanto, estes indígenas foram se dirigindo para Oco'y quando ficaram sabendo que aquela área tinha sido destinada aos que eram oriundos de Jacutinga.

Desta forma, estes deslocamentos motivados por pressões e demandas da sociedade brasileira foram, em grande parte, os responsáveis pela superlotação de Oco'y, que tem hoje cerca de 650 pessoas habitando 231 hectares de terra, dos quais apenas cerca de 80 hectares são agricultáveis. O restante da área é composto pela mata ciliar das margens do lago da Usina Hidrelétrica Itaipu Binacional, considerada Área de Preservação Permanente (APP) e por isto área não agricultável, pois é protegida contra o desmatamento para evitar o assoreamento do lago. 
A sobreposição da terra indígena e da Área de Preservação Permanente causa problemas em Oco'y ${ }^{6}$, segundo os nativos, por ser a área muito pequena. Esta sobreposição compromete a autonomia dos indígenas na administração desta Terra Indígena, pois eles são impedidos pela legislação ambiental brasileira de decidirem o que fazer com a área que lhes foi destinada. A situação é grave porque o tamanho da área de Oco'y que está disponibilizada para a agricultura, impede que as pessoas que vivem ali se sustentem e se organizarem de acordo com suas formas tradicionais. Portanto, devido ao pequeno tamanho da área os Ava-Guarani se deparam com a impossibilidade de plantarem em uma quantidade de terra suficiente para a produção agrícola, como também de terem um terreno com mata grande o suficiente para abrigar uma flora e fauna que propicie animais, remédios, madeira (para o fogo e para as construções tradicionais ${ }^{7}$ ) e alimentos.

A exigência de preservação que leva ao impedimento dos indígenas de utilizarem toda a terra que têm para a agricultura institui um paradoxo, já que esses indígenas reivindicam um lugar para viverem com mata. Como colocado acima, eles afirmam a necessidade dos remédios naturais, da madeira, dos alimentos e animais caçados e colhidos na mata, além da presença deste eco-sistema, que é fundamental para sua cosmologia e sistema de crenças mais geral, que se baseia na presença dos donos dos bichos e em uma ética de interação não abusiva com a natureza. Desta forma, espanta o fato da exigência da preservação justamente para aqueles que querem viver em uma terra com mata, pois, se é isso que eles querem e se é isso que eles têm, esta exigência perde o sentido. Contudo o problema é que em Oco'y tanto a terra (disponibilizada para a plantação), como a mata, são insuficientes: para plantar, para caçar, para coletar, para abrigar os donos dos bichos e os demais seres da mata.

Além da problemática que explica o tamanho diminuto da área indígena de Oco'y que é remetida a sua criação, esta área indígena foi, segundo os relatos nativos, diminuída pela entrada das fazendas na

\footnotetext{
${ }^{6} \mathrm{O}$ que não acontece em outras áreas de sobreposição de área de preservação da natureza e área indígena, das quais, inclusive, existem dados muitos positivos no que diz respeito à preservação da mata. Para a discussão específica sobre estas sobreposições, consultar Ricardo (2004).

${ }^{7}$ Para os Ava-Guarani é impensável construir uma casa de rezas, as chamadas ogas guasus, com alvenaria.
} 
ADRIANA REPELEVICZ ALBERNAZ - Interpretação do mundo e projetos ...

área indígena. Portanto, pequena desde sua criação, diminuída com o tempo pela ação dos fazendeiros, e tornada ainda mais diminuta mediante o grande número de pessoas que vieram de áreas indígenas do Paraguai e da Argentina e também das que estavam trabalhando para colonos da região, todas oriundas da hoje alagada área indígena de Jacutinga.

\section{As reivindicações por mais terras através da prática de acampamentos}

Dada esta realidade que é claramente avaliada pelos Ava-Guarani como imprópria para a existência diferenciada de seu sistema social, e mediante a ameaça deste sistema se "perder" e a vontade destes indígenas de que isto não aconteça, os Ava-Guarani de Oco'y têm feito ao longo do período que estão assentados em Oco'y um trajeto de manifestações com o objetivo de pressionar os órgãos competentes da sociedade brasileira a resolverem o problema da pouca quantidade de terra a eles destinada. Estes movimentos se baseiam principalmente na reivindicação de um território grande o suficiente para a atualização de suas formas de ser, regidas pelo seu sistema social tradicional.

Desde a criação da área indígena Ava-Guarani de Oco'y em 1982 até hoje já se contam quatro grandes acampamentos realizados por indígenas, que saíram desta área indígena para levantarem suas barracas em lugares estratégicos para chamar a atenção da sociedade brasileira - como refúgios ambientais da Usina Hidrelétrica Itaipu e Parque Nacional do Iguaçu. O primeiro acampamento ocorreu na segunda metade da década de $1990^{8}$ e teve como resultado a compra por parte da Usina Hidrelétrica Itaipu Binacional de uma área de 1700 hectares de terra no município de Diamante do Oeste (onde foi criada em 1997 o Tekoha Anhetété para onde foram transferidas cerca de 40 famílias indígenas que estavam em Oco'y). Em 2003 saiu de Oco'y um segundo grupo de indígenas para acampar como forma de manifestação e pressão para a resolução do problema da terra. Foram cerca de 80 pessoas que acamparam em vários lugares ${ }^{9}$ desde 2003 até o começo

\footnotetext{
${ }^{8}$ Num lugar chamado pelos indígenas de Paraná Porá, mas denominado oficialmente Refúgio Biológico Boa Vista, pertencente a Usina Hidrelétrica Itaipu Binacional.

${ }^{9}$ Entre eles em refúgios ambientais da Itaipu nos municípios de Terra Roxa e Santa Helena.
} 
do ano de 2007, quando, segundo informação do chefe do posto da Funai de Oco'y, esta instituição havia comprado um pedaço de terra para assentar estes indígenas acampados já há cerca de quatro anos. $O$ terceiro acampamento foi o mais curto e ainda não teve um resultado tão favorável como os dois primeiros. Este foi o acampamento realizado no Parque Nacional do Iguaçu que começou no dia 5 de setembro de 2005 e terminou de uma forma violenta, quando a polícia federal retirou a força de armas os cerca de 50 indígenas que estavam ali acampados. Porém com este acampamento o grupo liderado pelo atual cacique de Oco'y que retornou para esta área indígena conseguiu sensibilizar alguns órgãos institucionais do governo brasileiro, os quais têm procurado os indígenas para pensarem juntos uma solução para o problema da pouca quantidade de terra de Oco'y ${ }^{10}$. Entretanto uma parte do grupo que acampou no Parque Nacional do Iguaçu, encabeçados por uma liderança que se fortaleceu durante esse acampamento, não se conformando com a finalização do último movimento de protesto, organizou um quarto acampamento que começou em dezembro de 2005 e terminou em outubro de 2006. Este último acampamento teve lugar em um pequeno espaço de terra doado pela fazenda e cooperativa do Movimento dos Trabalhadores Rurais Sem Terra (MST) - chamada Itepa - antiga fazenda Mitacoré ${ }^{11}$-, que fica logo após o pedágio que separa os municípios de São Miguel do Iguaçu e Santa Terezinha, no lado direito da BR 277 em direção ao município de Foz do Iguaçu. Ele terminou quando a Funai conseguiu fazer um acordo com o grupo que estava acampado, levando-os para a área indígena de Inácio Martins, onde, disse-me o cacique de Oco'y, de acordo com a promessa da Funai teriam mais terras. Um das famílias que estava acampada, que é da única mulher rezadora ou xamã (Oporaíva no

\footnotetext{
${ }^{10}$ São estes os vereadores da Câmera Municipal de Foz do Iguaçu, além do Conselho Nacional do Meio Ambiente, que junto à Ordem de Advogados do Brasil, aprovaram uma moção entre os dias 8 e 9 de novembro de 2005. Por intermédio desta solicitaram à Fundação Nacional do Índio a resolução do problema de terras dos Ava-Guarani que estavam acamparam no Parque Nacional do Iguaçu.

${ }^{11}$ Fazenda com cerca de 1100 hectares que se estendem entre o lago da UH de Itaipu e a BR 277 no município de São Miguel do Iguaçu. Esta fazenda pertencia à família Andrade Vieira até março de 1997, quando foi tomada por intervenção Federal como pagamento das dívidas do Banco Bamerindus. No dia 16 de agosto de 1997, quando o Banco Central ainda estava decidindo a melhor maneira de utilizar essa fazenda, militantes do Movimento dos Trabalhadores Rurais Sem Terras ocuparam a fazenda, construindo nela uma cooperativa que funciona até hoje. (Cf. site da Revista Época, http://epoca.globo.com/edic/19991101/brasil9.htm e no site da Comissão Pastoral da terra, ocupações de terra por estado - Brasil- 1997, http://www.cptmac.com.br ).
} 
ADRIANA REPELEVICZ ALBERNAZ - Interpretação do mundo e projetos ...

idioma nativo) entre estes Ava-Guarani, voltou para Oco'y, justamente para fazer as rezas, já que o grupo de Oco'y ficou sem o seu principal rezador, que estava acampado na fazenda do MST e foi com este grupo para a área indígena de Inácio Martins.

\section{Projetos para o futuro Ava-Guarani: alternativas para a vida da humanidade}

Como contexto atual e recente pós acampamentos, e mesmo alternativos a estes - entendidos como práticas de mobilizações reivindicativas por mais terras, e que tiveram como base o contexto de limitação espacial causada pelas demandas da sociedade ocidental brasileira -, os Ava-Guarani de Oco'y, especialmente através da atuação e do discurso de suas lideranças políticas, têm como prática a construção de projetos para a restauração do que dizem ser seu sistema social tradicional indígena. A partir destes projetos os Ava-Guarani apresentam tanto uma certa aceitação das inovações da sociedade ocidental - como, por exemplo, a utilização de maquinarias para a produção agrícola, novas formas de habitação, a instituição da escola e a atuação do posto de saúde -, como também se colocam como críticos da "sociedade dos brancos" - forma como os Ava-Guarani se referem aos não índios em geral, com exceção dos negros -, e, baseados nesta critica, se julgam capazes de reverterem o quadro de destruição da terra, o qual identificam como causado pela ação irresponsável destes brancos. A reivindicação por mais terras também é o fator motivador para a realização destes projetos, pois uma das intenções colocadas pelas lideranças Ava-Guarani de Oco'y com a elaboração destes projetos é terem autonomia econômica e política em relação à sociedade brasileira. Pretendem assim deixar de depender das doações (principalmente de comidas) das instituições da sociedade brasileira através da produção própria de produtos agrícolas. Porém eles afirmam a necessidade de ter um espaço grande o suficiente de mata ${ }^{12}$, o que é sempre bem marcado por eles, pois a mata é o locus de relações fundamentais da cosmologia e mitologia Ava-Guarani, como das

\footnotetext{
${ }^{12}$ Cerca de $50 \%$ do território total da área que está sendo solicitada
} 
ADRIANA REPELEVICZ ALBERNAZ - Interpretação do mundo e projetos ...

relações que envolvem os cuidados dos donos de bichos, das águas e da mata com o que lhes pertence. Neste espaço criariam animais para a caça, plantas para os remédios utilizados nas curas feitas pelos oporaívas, e frutas para a coleta. O aspecto do cuidado que os "donos" dos animais, das águas e das mata têm com o que lhes pertence reflete uma lógica autóctone que se baseia em uma ética de não abuso e de não desperdício, que é base para outras práticas sociais. Estas relações são fundamentais para a interpretação que fundamenta a construção dos projetos de futuro tratados aqui.

É possível afirmar que neste equilíbrio delicado entre aceitação de inovações tecnológicas e de instituições da sociedade ocidental e o resgate de relações tradicionais, a utilização de maquinaria agrícola representa da melhor forma o primeiro termo, enquanto a reatualização da caça e da coleta, mediante a presença da mata de uma forma mais intensa ${ }^{13}$, representam bem o segundo.

Apresento aqui a afirmativa de que as construções destes projetos pelos Ava-Guarani de Oco'y - que é de re-atualização no futuro próximo de seu sistema social tradicional, com a incorporação de mudanças advindas da tradição ocidental -, exige uma re-elaboração da visão colocada pela literatura etnológica (METRAUX, 1967 e NIMUENDAJU, 1987) de que estes indígenas têm uma concepção do tempo cíclico, porque mítico, e pessimista em relação ao futuro. Afirmo que a prática e o discurso que envolve as construções destes projetos para o futuro demonstram como eles não podem mais ser vistos como nativos de uma sociedade onde o tempo é concebido e vivido como cíclico e fechado - características, segundo Lévi-Strauss (1996), de uma sociedade baseada nas reflexões trazidas pela ordem mítica, e por isto vistas como "sociedades frias".

As "sociedades frias", segundo Lévi-Strauss, são regidas pela lógica do mito e por isto não utilizam a mudança e a transformação como forma de representação, mas, ao contrário, priorizam a continuidade e a estabilidade em referência ao tempo mítico, que sempre é retomado. Já as "sociedades quentes" entendem a si mesmas

\footnotetext{
${ }^{13}$ Com destaque para os processos educativos propiciados pela presença da mata, como enfatizada pelos mais velhos sobre a possibilidade de com a mata educar as crianças a partir do conhecimento direto desta e do que vive nela (ex. os animais), e não apenas com o artesanato que produzem, e com livros, fotos, e lembranças.
} 
como estando num movimento perpétuo de transformação, alimentado por uma concepção dialética de criação e destruição que fundamenta a idéia ocidental de progresso. Lévi-Strauss afirma que enquanto as sociedades ocidentais se concebem como tendo sido feitas para mudar, sendo este o princípio de sua estrutura e de sua organização, as sociedades ditas "primitivas" são concebidas pelos seus membros como tendo sido feita para durar (LÉVI-STRAUSS, 1993, p. 326). Entretanto, para Lévi-Strauss a distinção fundamental entre "sociedades frias" e "sociedades quentes", não se refere ao fato da existência ou não de história nestas sociedades, mas sim ao fato de que algumas sociedades se representam a partir da história e outras não. Estes conceitos, que geraram discussões e interpretações equivocadas de que as "sociedades frias" seriam "naturalmente" sem história, apenas tipificam as sociedades que optaram ou não pela história ${ }^{14}$ como forma de autorepresentação privilegiada.

Os Ava-Guarani não se enquadram contemporaneamente neste modelo de sociedades que não se representam através da história, na medida em que fazem projetos por meio do quais propõem a incorporação de mudanças nas formas de produção agrícola e também no que se refere à educação, habitação e saúde, mesmo que estas mudanças sejam entendidas como fundamentais para a continuidade da sua existência diferenciada enquanto grupo indígena. Assim a situação atual dos Ava-Guarani de Oco'y parece ser melhor compreendida pela reflexão de Marshal Sahlins (1990) de que algumas vezes as mudanças são, para os que as defendem e vivem, estratégias para a permanência cultural, neste caso, para a permanência de fatores que julgam (os AvaGuarani) fundamentais para a existência diferenciada deles mesmos enquanto grupo indígena.

O mesmo motivo que leva ao questionamento da visão dos AvaGuarani de Oco'y contemporaneamente como um grupo social que é regido por uma visão de tempo cíclico, leva ao questionamento da afirmativa de que eles são, como também os conceitualizaram Metraux (1967) e Nimuendaju (1987), pessimistas em relação ao futuro. Eles demonstram pelas representações do que significa a prática de

\footnotetext{
${ }_{14}$ Entendendo aqui "história" como as representações e narrações sobre eventos, mudanças e permanências que se dão através do tempo.
} 
ADRIANA REPELEVICZ ALBERNAZ - Interpretação do mundo e projetos ...

construção destes projetos que não esperam uma catástrofe que destruirá a Terra no futuro próximo, esta que seria - seguindo a afirmação destes autores do que fundamenta o pessimismo como um dos traços diacríticos dos Guarani - tal qual a destruição que o mito conta já ter acontecido com a primeira Terra.

Vejamos: dizem os Ava-Guarani que antes deles nascerem existia uma Terra antiga que Nhanderu (palavra que significa Nosso Pai, divindade máxima do panteão Guarani), havia construído. Porém, depois que Kuaray e Jasi - filhos gêmeos de Nhandesy ou nossa mãe, o primeiro com Nhanderu e o segundo com um outro homem - foram para o Arã / céu, essa Terra foi destruída. Morreram todos que aqui viviam, pois a terra foi inundada pela água e depois queimada pelo fogo. Quando a água que inundou a Terra baixou, o sol a iluminou; mas como o céu estava muito próximo da Terra, o sol a queimou. Dizem que primeiro a Terra era preta e branca e que ambas queimaram. Depois que a Terra queimou, Nhanderu colocou o céu mais alto (tanto que não pode mais enxergá-lo) para a Terra não queimar. Nhanderu mandou Kyvykyvy (personagem mítico cujo é traduzido para o português) fazer a terra vermelha que existe até hoje, que foi socada e amassada para não queimar mais. Até hoje as mulheres socam a terra com os seus takuas, instrumentos musicais que as mulheres e meninas utilizam na casa de rezas quando cantam e acompanham os oporaívas ou rezadores. $\mathrm{O}$ ato de socar a terra, feito pelas mulheres e meninas na casa de rezas, também é o ato de ritmar o canto Ava-Guarani, o Kote'u. Este mesmo movimento de socar o chão e de ritmar o canto, é feito por Nhandesi em Nhanderu'uai (lugar cosmológico que fica no extremo leste do céu) onde também existe uma casa de rezas.

São três as versões que os Ava-Guarani contam para o próximo fim do mundo, que alguns esperam para 2010, e outros sem uma data certa, mas sempre o relacionando à conduta humana na terra e a possibilidade de reversão ou de adiamento deste fim através da busca da boa conduta, que significa seguir o nhandereko, os costumes dos Ava-Guarani. A expressão mais fundamental do nhandereko é, segundo eles mesmos, o Jeroke, a reza, as quais têm como tema recorrente os pedidos para Nhanderu não destruir este mundo. Entretanto, a versão mais recorrente entre os Ava-Guarani de Oco'y para o fim do mundo é a 
de que ele será como o que já aconteceu: a Terra será queimada pelo fogo provocado pelo sol. É esta versão que dá fundamento para uma interpretação de mundo e de futuro que influencia diretamente os rumos da política dentro da área de Oco'y e os projetos de futuro construídos por suas lideranças. Afirmam os expoentes dessa interpretação - especialmente as lideranças políticas e a única mulher que é rezadora em Oco'y, assim como seu marido, que é seu ajudante -, que se os brancos continuarem a destruir as matas, esta Terra queimará como aconteceu com a primeira Terra, pois sem a mata a Terra não tem proteção, o que faz com que fique exposta ao calor excessivo provocado pelos raios do sol, e como decorrência disto, que seja queimada. Vemos então uma transformação apresentada por esta versão mais corrente da interpretação do mito: se as outras duas versões que são menos correntes em Oco'y afirmam a espera impreterível da próxima destruição da Terra - mesmo que deixem aberta a possibilidade de negociação com as divindades através das rezas e da busca de uma conduta correta -, a versão mais corrente apresenta a destruição da Terra não como fim irrevogável e próximo, mas como uma possibilidade que é vista como uma conseqüência das ações erradas dos brancos.

Baseados nesta última versão os Ava-Guarani de Oco'y construíram uma interpretação de mundo que os legitima nas construções destes projetos onde apresentam não apenas a solução para continuarem a serem um grupo diferenciado e com um sistema social próprio, mas também uma solução para a vida da humanidade, na medida em que se pensam capazes de cuidar da terra e da mata, a qual os brancos já provaram serem capazes de destruir, e assim evitar a destruição desta Terra.

Porém, ao mesmo tempo em que estes projetos buscam a reatualização de uma organização social que está colocada como uma experiência passada (ex.: retomar a educação das crianças através do contato direto com a mata), eles também contemplam incorporações de mudanças advindas da tradição ocidental: além da maquinaria para a produção agrícola, novas formas de habitação, a instituição da escola e do posto de saúde, embora não se possa deixar de considerar que os indígenas têm contribuições significativas para a atuação específica 
ADRIANA REPELEVICZ ALBERNAZ - Interpretação do mundo e projetos ...

destas duas últimas instituições dentro da área indígena. Portanto, esses projetos têm a intenção de presentificar formas sociais que existiram no passado, mesclando-as com a incorporação de mudanças trazidas pela sociedade ocidental. Assim, são projetos que se baseiam em uma visão da passagem do tempo que é tanto baseada no mito possibilidade de destruição do mundo (METRAUX, 1967, p. 16) -, como também em uma leitura dos problemas que envolvem toda a humanidade no presente, especificamente os problemas ambientais causados pela ação dos "brancos".

Esta interpretação do mundo que mesmo tendo como base o repertório mítico, vê a destruição como conseqüência das ações erradas dos brancos - afirmando uma mudança nas interpretações do mito que vêem a irreversibilidade da destruição ditada pelas vontades das divindades, e projetando mudanças e melhorias para o futuro -, é melhor conceitualizada por uma outra passagem da obra de LéviStrauss. Nesta outra passagem o autor considera a possibilidade de transformação do mito em história, ou em outro gênero de narrativa. Este autor faz isto especificamente no capítulo XIV do livro Antropologia Estrutural Dois (1993), chamado "Como morrem os mitos", quando descreve o processo de transformação de um conjunto mítico em um gênero romanesco e também, sua reutilização para fins de legitimação histórica, que neste texto afirma que "pode ser de dois tipos: retrospectiva, para fundar uma ordem tradicional sobre um passado longínquo; ou prospectiva, para fazer desse passado o início de um futuro que começa a desenhar-se" (1993, p. 274). Os Ava-Guarani de Oco'y parecem estar utilizando o conjunto mítico, nos termos de LéviStrauss, exatamente como uma forma de legitimação histórica prospectiva (sem por isto deixar de ser também retrospectiva).

A compreensão desta mudança dos Ava-Guarani em relação ao modelo apresentado pela literatura etnológica é possível através da compreensão da interpretação de mundo nativa atual, que é baseada também nos relatos míticos. Estes relatos míticos apresentam e fundamentam formas de relações com a natureza, guiadas, como colocado antes, por uma ética de não abuso e não desperdício, idéias estas que estão relacionadas à concepção que os Ava-Guarani têm em relação à saúde humana. Isto se dá porque os Ava-Guarani concebem 
ADRIANA REPELEVICZ ALBERNAZ - Interpretação do mundo e projetos ...

que várias doenças podem ser causadas por uma má relação estabelecida com os seres da mata, como uma caça abusiva que levará a pessoa que caçou ou alguém de sua família à doença, na maioria das vezes causada por um susto provocado pelo dono do bicho. Esta doença é entendida como uma conseqüência desta caça abusiva, ou seja, uma caça que extrapola os limites daquilo que é necessário para a pessoa, sua família, e demais pessoas próximas se alimentarem. Temos então uma concepção de doença que está relacionada com o não cumprimento de regras sociais, estas que seguem a ética do não abuso e do não desperdício e que baseiam uma relação de respeito com os domínios da mata. São estes aspectos que fundamentam a compreensão dos AvaGuarani sobre o que é uma vida social saudável, compreensão que é justamente a motivação e a legitimação para a construção destes projetos de futuro que se colocam como alternativa para a vida da humanidade frente à ameaça de destruição do mundo.

Apresento aqui alguns dados sobre a organização social contemporânea destes indígenas, principalmente no que se refere à organização da - e as concepções do que é a - liderança política indígena, e suas relações com a reza - chamada no idioma nativo de Jeroke -, que é identificada pela maioria dos Ava-Guarani como o aspecto mais expressivo e importante da cultura - entenda-se sistema de crenças, valores, símbolos e costumes - Ava-Guarani ${ }^{15}$, e todo o universo a ela relacionado, que é composto pela mitologia, pela cosmologia e pelas histórias do tempo em que Deus estava na Terra, aspetos já assinalados acima. Estes dois aspectos - organização e concepções em relação à liderança política, e o universo da religiosidade - são fundamentais para a compreensão destes projetos de reatualização do sistema social tradicional: o primeiro por serem as lideranças políticas os agentes privilegiados na construção e apresentação destes projetos; e os segundo por ser do conjunto de crenças e significados relacionados à reza, a inspiração, a motivação e a legitimidade para a construção destes projetos de futuro. Estes, como dito antes, extrapolam a justificativa da existência diferenciada do

\footnotetext{
${ }^{15}$ Com exceção dos poucos Ava-Guarani que além de não praticarem a reza, não a acham importante, pois é recorrente em Oco’y que mesmo aqueles que não vão à casa de rezas hoje em dia, afirmarem a sua importância, tanto no sentido espiritual e de cura, como de lugar onde se revive e se aprende as formas tradicionais e os conhecimentos dos antigos.
} 
próprio grupo na medida em que são projetos que também têm como objetivo evitar a destruição da terra.

\section{O papel privilegiado da liderança política na construção de projetos de futuro}

O chefe político em Oco'y é chamado correntemente de cacique, porém os Ava-Guarani sabem e afirmam que este termo passou a ser usado a partir do contato com os brancos. O nome nativo utilizado para denominar o chefe político é Nhanderuvicha, que significa nosso pai geral ou de todos. O significado deste termo demonstra a estreita ligação entre as relações de parentesco e as relações políticas entre os Ava-Guarani, já que é formado pelo termo que designa pai - ru -, acrescentado do prefixo nhande, que é o pronome pessoal inclusivo da primeira pessoa do plural, nós, e adjetivo possessivo, também inclusivo, nosso, e do sufixo vicha, que significa de todos ou geral, formando o significado do grupo como uma grande família, onde a pessoa que responde por ele é visto como o pai ${ }^{16}$. Isto também se dá no âmbito da religiosidade, já que também Deus e avô são chamados correntemente de Nhanderu (Nhande = Nós; $R u=$ pai), nosso pai, assim como as avós e a Deusa do panteão Guarani (também chamada mãe de Deus e ou mulher de Nhanderu) são chamadas de Nhandesi (Nhande = nossa; Si $=$ mãe), que significa nossa mãe. $O$ avô, que também é chamado no idioma nativo de chamo'i e a avó, chamado também de chara'y, são figuras centrais para a religiosidade Ava-Guarani, sendo que os(as) rezadores(as) ou oporaívas são, em geral, avôs ou avós (existe uma rezadora mulher em Oco'y), e mesmo aqueles avôs ou avós que não

\footnotetext{
${ }^{16}$ Na primeira vez que o cacique de Oco’y me falou sobre o termo nativo que designa o chefe político, que seria equivalente ao usual termo cacique, ele utilizou o termo Oreruvicha que significa nosso pai geral (Ore $=$ Nós; $r u=$ pai, $v i c h a=$ geral, de todos), porém formado com o pronome pessoal da primeira pessoa do plural ore, que também significa nós, mas que excluí uma parte de um dado contexto comunicativo, ou seja, um nós que é colocado em um contexto onde existe outros, diferentes, e onde estes estão excluídos. Como é sabido, os Guarani tem dois termos que ocupam a posição do pronome pessoal e adjetivo possessivo da primeira pessoa do plural: Nhande, que significa um nós ou nosso que é inclusivo de todas as pessoas que fazem parte do contexto comunicativo, e Ore, que tem o mesmo significado, mas que exclui uma parte deste contexto comunicativo. No caso citado acima, o cacique utilizou o pronome Ore, pois estava se referindo ao chefe político que é de todos os Ava-Guarani de Oco'y, mas não da pesquisadora que estava ali conversando com ele.
} 
ADRIANA REPELEVICZ ALBERNAZ - Interpretação do mundo e projetos ...

fazem a reza na casa de rezas, as fazem em suas casas para benzer e curar seus filhos e netos ${ }^{17}$.

Todas as pessoas em Oco'y que prestam algum serviço à comunidade - seja um serviço remunerado, como os cargos de professores indígenas e de agente de saúde indígena, ou os cargos nãoremunerados relacionados à organização da comunidade, como os de liderança política ou os relacionados à Associação Comunitária - dizem que estão desempenhando estes papéis porque a comunidade os escolheu. Estas pessoas dizem que quem tem total poder de decisão nos assuntos internos da área indígena de Oco'y é a comunidade. Este discurso, repetido inúmeras vezes especialmente pelas lideranças políticas Ava-Guarani, demonstra a importância do conceito de comunidade para a compreensão deste grupo indígena, e corrobora a tese de Pierre Clastre (2003) de que o poder político encontra-se entre os Tupi-Guarani localizado na sociedade e não na figura de seu chefe político: ao menos isto é o que é admitido conscientemente, existindo na prática, evidentemente, formas específicas de articulação de pessoas e grupos, as que são feitas primeiramente em torno à família extensa. A escolha das lideranças pela comunidade segue principalmente a observação do critério do interesse demonstrado em trabalhar ou dedicar-se ao grupo, ou seja, a pessoa que será um líder tem que demonstrar seu interesse e capacidade de trabalho para a comunidade antes de ser escolhido para a função de liderança. Entretanto, além deste interesse demonstrado em trabalhar para a comunidade, algumas outras características são valorizadas e mesmo ditas necessárias ao aspirante a ser um bom chefe político, que são: o conhecimento da língua portuguesa e o conhecimento de como funciona a sociedade dos brancos. Os Ava-Guarani de Oco'y, principalmente as suas lideranças políticas, dizem que estas qualidades são indispensáveis para o diálogo e as negociações com os brancos, ações esperadas de uma liderança. 0 cacique de Oco'y afirma ainda que a valorização destas se justificam pela necessidade que a liderança têm de saber negociar com os brancos para defender a comunidade, pois, como afirma: "hoje os brancos não matam mais os índios com armamento (como fizeram no passado), só

\footnotetext{
${ }^{17}$ O privilégio da relação de filiação para as curas proporcionadas pelas rezas em Oco'y será melhor discutida no trabalho de tese que apresentarei ao Programa de Pós-Graduação de Antropologia Social da UFSC em março de 2008.
} 
ADRIANA REPELEVICZ ALBERNAZ - Interpretação do mundo e projetos ...

politicamente, nos reprimindo. Então alguns têm que abrir os olhos, se reunir e trocar idéia para pegar uma pessoa para nos assessorar a fazer documentos". O chefe político é tido como a pessoa que deve assessorar na confecção destes projetos, além de ser a pessoa capacitada para a negociação com a sociedade dos brancos.

O atuar através da confecção de projetos é o aspecto da prática contemporânea dos brancos que é mais enfatizada pelas lideranças políticas em Oco'y. É justamente este aspecto que estes indígenas dizem ser necessário aprenderem com os brancos e deles incorporarem como prática política. Através desta forma de estabelecimento de relação com o que é caracterizado como exterior ao seu sistema social (neste caso, com a sociedade dos brancos), os Ava-Guarani identificam características do "outro" como primeiro passo à transformação neste "outro", demonstrando uma forma de agir e de pensar que nos termos de Viveiros de Castro (1986) podemos conceitualizar como característico de um "devir outro" (1986, p. 66). Desta forma, os AvaGuarani de Oco'y, principalmente através de suas lideranças políticas, colocam a necessidade do conhecimento da sociedade dos brancos (suas práticas políticas e também da língua) para através deste conhecimento saberem se relacionar, dialogar e negociar, mas também, para incorporarem práticas e se transformarem através de incorporações do que julgam práticas positivas. Vemos assim que menos do que sociedades sem projeto (sans projet) ou fora do projeto (hors projet) como afirma Jean-Pierre Boutinet $(2005$, p. 3 ) serem as comunidades tradicionais ou não ocidentais/modernas, quando apresentando a genealogia do termo identifica a prática de elaboração de projetos com a tradição ocidental, os Ava-Guarani se mostram capazes de construírem estes projetos. Isto, mesmo que se transformando através da incorporação do que eles também (concordando como Jean-Pierre Boutinet) identificam com um dos traços mais marcantes da tradição ocidental ou sociedade dos brancos.

\section{A atuação do complexo profético da busca da Terra Sem Mal como motivador à construção dos projetos para o futuro}


ADRIANA REPELEVICZ ALBERNAZ - Interpretação do mundo e projetos ...

Toda a história recente dos Ava-Guarani na região do oeste paranaense contada por eles mesmos - incluindo ai os três movimentos de saída de Jacutinga - é de expulsões e de deslocamentos forçados por demandas da sociedade ocidental. Os mais velhos contam que habitavam a área que foi destinada ao Parque Nacional do Iguaçu a partir de 1939, assim como o lugar onde está hoje o Aeroporto Nacional de Foz do Iguaçu, ambos lugares que tiveram que deixar quando da execução dos projetos de construção, no primeiro caso, do Parque Nacional do Iguaçu, e no segundo, do Aeroporto de Foz do Iguaçu. Dizem também muitos dos Ava-Guarani que habitam hoje em Oco'y que eles habitaram o lugar que hoje é conhecido como o bairro Três Lagoas, também em Foz do Iguaçu, antes de irem para Jacutinga, de onde também foram pressionados a sair pela ação dos brancos.

Entretanto Jacutinga é o lugar de maior recorrência nos relatos dos nativos sobre o seu passado recente, por ser o último lugar entendido como área indígena onde esses Ava-Guarani habitaram no Brasil antes de ser criada a área indígena de Oco'y, e também, pela coleção de ações negativas dos brancos em relação aos indígenas, como as já citadas pressões do INCRA e da UH Itaipu Binacional para que os indígenas deixassem a área em que habitavam.

Os deslocamentos que estes indígenas contam serem motivados por suas demandas próprias são os relacionados às visitas aos parentes, à busca de cura dos oporaívas, e ao estabelecimento de novos casamentos. Eles são considerados fundamentais para a continuidade deste grupo indígena que é exogâmico no que se refere aos laços de consangüinidade $^{18}$, e endógamos no que se refere ao grupo étnico, já que não apreciam os casamentos com não Ava-Guarani ${ }^{19}$.

O complexo profético que anima a busca do Yvy Ymarae'y ou conforme a tradução que é aceita correntemente em Oco'y por aqueles que falam em português -, Terra Sem Mal, é pano de fundo das motivações para estes deslocamentos feitos para visitar parentes, dado que os nativos afirmam que não só no passado - quando eles podiam se deslocar para onde bem quisessem, pois o branco ainda não havia chegado para estabelecer fronteiras e limites -, mas que no presente

\footnotetext{
${ }^{18}$ Os casamentos entre primos, sejam paralelos ou cruzados, assim como o entre tio (a) e sobrinha (o), não são permitidos.

${ }^{19}$ Como com brancos, Kaigang e Mbyá.
} 
ADRIANA REPELEVICZ ALBERNAZ - Interpretação do mundo e projetos ...

também o caminhar é uma conduta valorizada ${ }^{20}$. Desta forma, o deslocar-se não é visto como uma conduta estranha e inaceitável. Além disto, a busca do Yvy Marae'y não é apenas um "se deslocar" no espaço em busca de um lugar específico, já que também representa uma busca espiritual. Porém mesmo os deslocamentos no espaço - que ocorreram de fato e foram comprovados pelos documentos arqueológicos, históricos e etnográficos ${ }^{21}$, e que continuam a acontecer mas em termos diferentes das grandes migrações apresentadas pela literatura, já que contemporaneamente geralmente não são realizados apenas por grupos menores, a maioria das vezes, por grupos familiares - requerem um preparo específico que se relaciona à prática da reza, da dança e do canto $^{22}$ - praticas que compõem o fundamento da espiritualidade AvaGuarani. Esta espiritualidade engloba a idéia de ascensão espiritual, conseguida através das práticas anteriormente colocadas. Estes aspectos compõem o preparo espiritual necessário para encontrar o caminho para esta Terra Sem Mal, vista algumas vezes como estando localizada no oeste, outras no leste, mas também vista estritamente como uma ascensão espiritual e - idealmente - também física.

Vemos então que o complexo de crenças e práticas relacionado à busca do Yvy Marae'y está intrinsecamente relacionado à prática da reza, e da concepção de sua importância. Assim, se a reza é o aspecto mais importante para, e que melhor identifica, os Ava-Guarani, e se um dos seus mais preciosos fundamentos é o complexo de busca do $Y_{v y}$ Marae' $y^{23}$, então parece óbvio que este complexo esteja relacionado com a forma como concebem os seus deslocamentos contemporâneos, em especial os que são motivados por suas demandas próprias de visitas aos parentes e da busca de novos casamentos. Seguindo o mesmo raciocínio apresento a hipótese de que este complexo de busca do $Y_{v y}$ Marae'y esteve ativo na forma como os Ava-Guarani interpretaram os

\footnotetext{
${ }^{20}$ Vários Ava-Guarani em Oco'y me disseram que eles viajam muito, ou deslocam-se, porque este é o jeito mesmo do índio Guarani.

${ }^{21}$ Destaco os relatos dos missionários jesuítas, dos viajantes do século XVIII e XIX, dos cronistas, das hipóteses baseadas em dados arqueológicos para os deslocamentos dos Guarani do Norte para o Sul do país (MELIÁ, 1992), a tese de Pierre Clastres em A sociedade contra o Estado (2003) e o relatos de Curt Nimuendaju no livro As lendas de criação e destruição do mundo dos Apapocuva Guarani (1987).

${ }^{22}$ Especificamente sobre os deslocamentos feitos pelos Ava-Guarani (Nhandéva) e Mbyá pela região da tríplice fronteira entre a Argentina, Brasil e Paraguai, consultar o trabalho de Evaldo Mendes da Silva (2007).

${ }^{23}$ Concebido como um lugar onde não existe a falta de alimentos e onde se vive todo o tempo a rezar, a dançar e a cantar com os Deuses e os outros seres aguyje, ou seres perfeitos.
}

Espaço Ameríndio, Porto Alegre, v. 1, n. 1, p. 146-169, jul./dez. 2007. 
ADRIANA REPELEVICZ ALBERNAZ - Interpretação do mundo e projetos ...

deslocamentos forçados pelas demandas da sociedade ocidental brasileira, mesmo que hoje os entendam como imposição ${ }^{24}$. Esta interpretação explicaria porque estes indígenas acabaram por sair de seus territórios mesmo antes de uma ação direta de alguma instituição ocidental, como foi o caso da saída de várias famílias de indígenas de Jacutinga quando começaram a circular as notícias que aquele território seria alagado. Fundamento esta hipótese no raciocínio apresentado pela literatura etnológica de que este complexo atuou como motivador de fugas dos problemas instaurados nos seus devidos contextos: sejam eles os relativos à organização incipiente de um poder político centralizado, como defendeu Pierre Clastres (2003), de fuga dos problemas causados pelo colonialismo e missionarismo europeu e que provocou a interiorização dos indígenas, como afirma Alfred Metraux (1967), ou ainda fuga da destruição do mundo, previsto pela mitologia, como afirmou Curt Nimuendaju (1987).

A organização de um movimento indígena que em grandes termos influencia a forma de atuação das lideranças políticas ${ }^{25}$ dentro da área indígena de Oco'y, e também a atuação de organizações pro-indígenas, como a atuação na década de 1980 e 1990 do Conselho Indigenista Missionário (CIMI) tem um papel fundamental no que se refere à mudança da atuação deste complexo de busca do Yvy Marae'y. Desta forma parece que contemporaneamente menos do que incentivar fugas, deslocamentos ou interiorizações, o complexo de busca da Terra Sem Mal passa a atuar como base de construção de projetos de futuro, que, como colocado anteriormente, não apenas apresenta a possibilidade da continuidade da existência diferenciada deste grupo indígena, mas também, justamente por esta existência diferenciada, se coloca como alternativa para a vida de toda a humanidade na medida em que se julga capaz de evitar a destruição do mundo.

\footnotetext{
${ }^{24}$ Isto não ameniza a responsabilidade das instituições da sociedade ocidental na retirada dos indígenas de seus territórios de ocupação tradicional.

${ }^{25}$ Isto porque as lideranças políticas Ava-Guarani de Oco’y participam de encontros regionais e nacionais organizados pelo movimento indígena, como o encontro feito em memória a morte de Sepé Tiaraju, realizado entre os dias 3 a 7 de fevereiro de 2006, em São Gabriel, RS, para o qual dirigiu-se um ônibus com Ava-Guarani de Oco'y e suas lideranças políticas. Neste período eu estava realizando o trabalho de campo na área indígena de Oco'y.
} 
ADRIANA REPELEVICZ ALBERNAZ - Interpretação do mundo e projetos ...

\section{Conclusão}

Afirmo como base nos dados do trabalho de campo realizado entre janeiro e junho de $2006^{26}$ na área indígena Ava-Guarani de Oco'y, que devemos considerar uma transformação na concepção que estes indígenas têm do tempo, que agora não mais se apresenta como uma concepção cíclica e pessimista em relação ao futuro, mas sim como uma concepção aberta em relação ao tempo, a que possibilita o planejamento de uma atuação positiva que evitará o fim do mundo. A destruição do mundo, embora seja vista como sendo possível de acontecer - porque dizem que Nhanderu (divindade máxima do complexo religioso Ava-Guarani), como já fez uma vez, pode fazer isto de novo quando quiser -, é vista hoje pelos Ava-Guarani de Oco'y não somente como um ato que pode ser provocado pela divindade, mas como conseqüência de ações humanas bem marcadas. Todavia, agora não como conseqüência dos atos de um ser humano genérico que poderia se confundir com os próprios Ava-Guarani, mas de um ser humano específico, o branco com suas práticas consideradas destrutivas. É a causa que os Ava-Guarani identificam desta destruição do mundo - as ações irresponsáveis dos brancos em relação à natureza e também em relação aos próprios indígenas - que melhor diferencia a forma como os Ava-Guarani de Oco'y se vêem, sendo que desta constatação vêem a possibilidade de reverter sua conseqüência, a destruição do mundo, através da ação positiva da realização de seu projeto de futuro.

Portanto, ao contrário de pessimistas, os Ava-Guarani se colocam como agentes na construção de um futuro que não tem necessariamente a catástrofe como fim, e do qual não precisam fugir. Logo, os Ava-Guarani se apresentam não como uma sociedade com uma concepção cíclica e fechada em relação à passagem do tempo dado que a destruição do mundo se coloca agora como uma possibilidade que está estritamente vinculada às ações erradas dos brancos -, mas com uma concepção aberta da passagem do tempo,

\footnotetext{
${ }^{26}$ Somado a duas visitas a área indígena Ava-Guarani de Oco’y feitas anteriormente ao trabalho de campo contínuo e outras 10 visitas feitas durante a passagem do ano de 2006 para o ano de 2007.
} 
ADRIANA REPELEVICZ ALBERNAZ - Interpretação do mundo e projetos ...

onde é possível uma ação positiva, que tem como base os ideais da Terra sem Mal.

Vemos então como esta interpretação de mundo Ava-Guarani diferencia-se do modelo mitológico apresentado pela literatura que afirma o pessimismo e a resignação dos Guarani em relação ao futuro, na medida em que estes não esperam um cataclismo como fim irreversível e próximo desta Terra, o qual os motivava a fugas. Ao contrário de apresentarem-se como resignados com a próxima destruição da Terra, os Ava-Guarani se vêm hoje como capazes de reverter o quadro que identificam como causa da destruição - a falta de cuidado com a Terra, principalmente no sentido da devastação da natureza, levadas à cabo pelos brancos -, e assim evitar a destruição. Estas causas, identificadas como exteriores a seu sistema social, poderiam ser revertidas a partir da realização do projeto nativo. Os AvaGuarani de Oco'y colocam assim em destaque os problemas de desequilíbrio ambiental e de devastação das matas, incorporando o branco e suas formas de ser na leitura que fazem do mundo e do desenvolvimento da história, já que apontam as conseqüências na forma de organizar o mundo apresentadas até hoje pelos brancos. Desta forma apresentam soluções e possibilidades de ação histórica que os capacita a evitar o que seria o destino mítico de destruição do mundo.

\section{Referências Bibliográficas}

ALMEIDA, Rubem T. Laudo Antropológico Sobre a Comunidade GuaraniÑandeva do Oco'y/ Jacutinga - PR. Rio de Janeiro: Associação Brasileira de Antropologia, 1995.

BOUTINET, Jean-Pierre. Anthropologie du projet. França: Edições Quadrilage, 2005.

BRANT DE CARVALHO, Maria Lucia. Relatório antropológico: população indígena Ava-Guarani (nhandéva). Terra indígena de Oco’y. Município de São Miguel do Iguaçu. Paraná. Brasil. Laudo antropológico solicitado pelo Ministério Público Federal e Justiça Federal de Foz do Iguaçu. Antropóloga nomeada pela Funai. (no prelo), 2004. 
ADRIANA REPELEVICZ ALBERNAZ - Interpretação do mundo e projetos ...

CARVAlHO, Edgar de Assis. Ava-Guarani do Oco'i-Jacutinga. Parecer do antropólogo designado pela Associação Brasileira de Antropologia. Paraná, 1981.

CLASTRES, Pierre. A Sociedade Contra o Estado. São Paulo: Cosac \& Naïfy, 2003.

LÉVI-STRAUSS, Claude. Introdução: História e Etnologia \& A Noção de Estrutura em Etnologia In: Brasileiro, 1996. Antropologia Estrutural. Rio de Janeiro: Editora Tempo . Antropologia Estrutural Dois. Rio de Janeiro: Biblioteca Tempo Brasileiro, 1993.

Mito e Significado. Portugal: Edições 70, 1978.

MELIÁ, Bartomeu. La Lengua Guaraní Del Paraguay: Historia, sociedad y literatura. Madrid, España: Editorial MAPFRE. 1992.

MÉTRAUX, Alfred. Religions et magies indiennes d'Amérique du Sud. França: Edições Gallimard, 1967.

NAVARRO, Eduardo de Almeida O domínio da língua castelhana sobre o Guarani Paraguaio. Revista Philologues, Rio de Janeiro, 2004. Revista on-line. Disponível em: http://filologia.org.br/livraria/sumários/philologus_29(sumario).htm

NIMUENDAJU UNKEL, Curt. As lendas da criação e destruição do mundo como fundamentos da religião dos Apapocúva-Guarani. São Paulo: Editora Hucitec/ Editora da Universidade de São Paulo, 1987.

SAHLINS, Marshal. Ilhas de História. Rio de Janeiro: Zahar, 1990.

SILVA, Evaldo Mendes. Folhas ao vento: A micromobilidade de grupos Mbyá e Nhandéva (Guarani) na Tríplice Fronteira. Tese (Doutorado em Antropologia Social), Rio de Janeiro: Museu Nacional da Universidade Federal do Rio de Janeiro, 2007.

VIVEIROS DE CASTRO, Eduardo. Araweté: Os deuses canibais. Rio de Janeiro: Jorge Zahar Editor/ANPOCS, 1986. 